\title{
公路桥梁专业化发展的关键问题研究
}

钟胜

鹤峰县农村公路管理局

DOI:10.32629/btr.v2i1.1769

[摘要] 随着现代社会进步和发展中,我国经济水平不断增长,公路事业呈现良好的发展前景。公路桥梁工程建设和发展,在现 代科学技术支持下, 逐渐朝着专业化方向发展,对于城市化现代化建设具有积极作用。尤其是在科学技术不断推陈出新下,公路 桥梁建设中很容易受到客观因素影响,埋下一系列质量隐患,影响到使用安全和使用寿命。基于此,本文就公路桥梁专业化发展 中的问题进行剖析,从多角度优化设计,以便于推动公路桥梁工程建设和发展。

[关键词] 公路桥梁; 专业化发展; 梁式桥; 混凝土

自我国改革开放以来, 公路规模不断扩大, 公路事业呈 现蓬勃发展前景。作为公路工程建设重的重要内容, 越来越 多的横跨江河与海湾的桥梁涌现。普通公路和高级公路的桥 梁形式多样化, 为了提升工程质量, 维护公路运输安全, 推动 公路桥梁专业化发展受到高度关注。基于此, 应该不断推动 技术和工艺创新, 打造高质量的公路桥梁工程, 为社会生产 生活提供便捷的同时, 推动运输业健康持续发展。通过公路 桥梁专业化发展问题分析研究, 对于连通各个区域和经济发 展具有重要作用。

\section{1 公路桥梁中的常见桥型}

1.1 拱式桥

此种公路桥梁形式较为常见, 主要是通过拱肋承受结构 整体压力。为了保证工程质量, 需要选择合适的材料, 包括坅 工和钢筋硂。拱式桥在技术不断改进和完善, 当前的拱式桥 跨径逐渐多样化。

\section{2 板式桥}

在公路桥梁建设中, 板式桥梁形式较为常见, 作为一种 基础结构桥梁形式, 工程结构采用预应力混凝土和钢筋混凝 土。在具体施工中, 板式桥结构表现为空心结构和实心结构 ${ }^{[1]}$ 。 通常情况下, 实心结构多应用在跨径不超过 $13 \mathrm{~m}$ 的板式桥梁, 此 后桥梁的挖空量较小, 可以选择预制拼接方式便于后续施工 活动展开。如果跨径超过 $13 \mathrm{~m}$ 的板式桥则采用空心板结构, 相 较于实心板结构操作较为复杂, 难度大, 很容易受到客观因素 影响到质量和安全。通常情况下, 此种结构工程多为后张预 应力混凝土结构和先张预应力混凝土结构, 其中先张预应力 施工中, 采用钢绞线和冷拔钢丝, 而后张预应力法则以单根 钢绞线和多跟钢绞线为主, 然后立模现浇。需要注意的是, 空心板式桥在孔洞制作中, 通常是采用一次性成孔材料和胶 囊实现, 但无论是预应力混凝土结构还是钢筋混凝土结构, 均需要采用高标号的混凝土材料。结合具体板式桥施工要求, 适当调整空心板宽度, 大概在 $1.5 \mathrm{~m}$ 左右, 可以实现板式桥吊装 能力最大化 ${ }^{[2]}$ 。

1.3 梁式桥

我国当前的公路桥梁中梁式桥种类多样, 从结构角度可
以将其划分为连续梁、悬臂梁和简支梁, 从截面形式角度进 行分析, 可以划分为 $\mathrm{T}$ 型梁、箱型梁和槽型梁几种。由于梁式 桥自身跨径多样, 凭借此种桥梁结构跨境大优势, 在实践中 得到了广泛应用。

\section{2 优化中小跨径斜交桥梁设计}

中小跨境斜交桥梁设计是公路桥梁工程建设中的重要 内容, 设计是否合理直接关乎到公路桥梁专业化发展。在具 体工程建设中, 中小跨境斜交桥梁设计, 保证桥梁结构具备 较强的耐久性, 降低施工难度, 提升施工质量。结合桥梁区域 位置情况, 优化中小跨境斜交桥梁设计, 提升设计合理性的 同时, 便于后续施工活动有序开展 ${ }^{[3]}$ 。其次, 斜交桥梁在弯道 区域设置, 则需要在具体设计中优化斜交桥梁结构, 促使复 杂的结构简化, 以便于减少构建类型, 便于后续的施工装配 活动更顺利展开。需要注意的是, 桥梁构建设计统一尺寸, 规避不必要的麻烦。最后, 在中小跨境斜交桥梁设计中, 在保 证设计质量的同时, 还要注重桥梁美观性, 在降低成本的同 时, 提升工程质量和效益, 更大范围推广和应用。

\section{3 规范化施工放样}

施工放样是公路桥梁施工中的一项重要环节, 如果施工 放样不合理, 各项参数把握不充分, 可能埋下一系列质量隐 患。通常情况下, 公路桥梁施工放样工作中, 根据工程设计要 求选择合理的仪器设备和测量方法, 对比分析设计图和实际 工程中的差异, 保证测量工作专业性 ${ }^{[4]}$ 。由于施工放样和侧 图工作自身特性, 具有对比性特点, 这就需要施工放样中了 解建筑物设计尺寸, 在此基础上挖掘建筑物构成部分和控制 点的位置关系。在获取精准可靠的施工放样数据后, 进行精 准计算, 把握建筑物的距离、高程和角度等参数。最后, 结合 工程控制点要求, 将设计落实到实处, 规范化施工。按照一定 次序进行施工放样, 优化整体结构布局, 在保证施工高质量 的同时, 提升施工放样严密性。做好公路桥梁施工放样工作, 有助于推动公路桥梁专业化发展, 为后续工程施工活动有序 开展提供指导, 创造更大的经济效益 ${ }^{[5]}$ 。

\section{4 应用高性能混凝土}

由于工程自身特性, 混凝土用量较高, 混凝土质量高低 
直接关乎到公路桥梁整体工程质量。这就需要在公路桥梁工 程施工中, 根据质量标准应用高性能混凝土, 优化高性能混 凝土配合比, 为后续的公路桥梁专业化发展奠定基础。为了 保证施工质量, 高性能混凝土在公路桥梁施工中应用, 应该 遵循相应标准进行。首先, 控制所选择的混凝土凝胶材料强 度, C40 以上的混凝土凝胶材料用量控制在 $400 \mathrm{~kg} / \mathrm{m}^{3}$ 以内; 不超过 C50 等级的混凝土胶凝材料用量则在 $450 \mathrm{~kg} / \mathrm{m}^{3}$ 以内; C60 等级以上的混凝土凝胶材料用量控制在 $500 \mathrm{~kg} / \mathrm{m}^{3}$ 以内。 其次, 施工中需要优化高性能混凝土配合比, 适当添加磨细 矿渣粉和优质粉煤灰材料, 改良混凝土性能同时, 有效提升 高性能混凝土的抗裂性和耐久性 ${ }^{[6]}$ 。

高性能混凝土配合比设计中, 加入掺合料之前需要进行 试验工作, 符合工程建设要求后方可投入到工程建设中。预应 力混凝土中, 粉煤灰用量是胶凝材料的 $1 / 5$, 粉煤灰含碳量不 超过 $2 \%$ 。根据高性能混凝土材料要求适量掺加外加剂, 以复合 外加剂为主, 这样即便是面对耐久性要求较高的混凝土结构, 则需要进行试验来对比分析混凝土和胶凝材料抗裂性能, 优 化配合比, 保证试验结果精准可靠。此外, 结合技术标准控制 高性能混凝土中的含碱量, 氯离子含量在总质量 $0.1 \%$ 以下。

\section{5 加强立柱施工和模板施工}

标识立柱重心坐标, 严格控制立柱纵横线控制桩, 避免 桩位偏移; 绑扎钢筋, 结合立柱放样变现检查钢筋保护层厚 度, 如果存在偏差及时校准, 重新绑扎钢筋。在模板施工中, 采用框架式定型钢模, 两片单片侧模拼装而成, 确保几何尺 寸和平整度符合施工要求; 模板安装则采用分块吊装方式, 结合施工要求拼装成形; 浇注钻孔桩时, 对预埋钢筋固定处 理, 并在各个立柱之间设立一根方木对撑; 在模板间敷设厚 度 $5 \mathrm{~mm}$ 左右的海绵条, 固定后切去外露海绵, 使用水泥砂浆密 封处理 ${ }^{[7]}$ 。

在硂浇筑前, 需要检查模板稳定性和钢筋保护层厚度, 并对模板上的杂质充分清理干净。采用自拌制硂, 优化配合 比设计, 运输到施工现场后借助洜入模。由于立柱较高, 内箍 筋密度大, 如果直接从模板顶部入模, 可能导致硂离析影响
到整体质量。所以, 可以根据施工要求制作一套串筒, 砤浇筑 到达一定高度后及时拆除, 借助吊车实现。分层浇筑硂材料, 厚度在 $40 \mathrm{~cm} \sim 50 \mathrm{~cm}$, 并进行充分的振捣, 然后现场浇筑。硂浇 筑后但尚未初凝前, 顶部砤需要二次振捣, 保证砤密实度。

砤浇筑完成后, 为了保证施工质量, 避免质量缺陷的出 现, 应该积极进行养护处理, 在上面覆盖一层塑料薄膜, 并定 期洒水养护, 避免水分过快流失加剧内外温度差异, 出现裂 缝问题。拆模时则需要结合气温情况进行, 保证硅强度符合 要求, 温度达到 $20^{\circ} \mathrm{C}$ 以上即可拆模, 未达到 $20^{\circ} \mathrm{C}$ 则需要等待 $48 \mathrm{~h}$ 。拆模期间注意不要破坏浇注成型的硂, 避免整体质量和 美观受到影响。

\section{6 结束语}

综上所述, 在城市交通运输业蓬勃发展下, 公路桥梁工 程不断扩大, 推动公路桥梁专业化发展是必然选择。这就需 要整合资源, 明确公路桥梁专业化发展中的关键问题, 选择 合适的桥梁结构和高性能混凝土, 在工程结构优化设计基础 上规范化施工, 保证公路桥梁施工质量, 推动公路运输业健 康持续发展。

\section{[参考文献]}

[1]任金玲.土木工程中公路桥梁专业化发展的关键问 题研究[J].交通世界,2018,31(30):78-79.

[2]张守峰.对高速公路桥梁专业化养护工程施工技术的 探讨 [J].工程建设与设计,2017,24(16):105-106.

[3]王敬.专业化高速公路桥梁养护施工技术要点与措施 研究[J].江西建材,2015,11(23):145.

[4]李磊.土木工程中公路桥梁专业化发展的四个关键点 [J].产业与科技论坛,2014,13(12):211-212.

[5]宋阳.专业化高速公路桥梁养护施工技术浅析 [J]. 黑 龙江科技信息,2014,20(06):192.

[6]张敬标.高速公路桥梁养护专业化社会化方式研究 [J].安徽建筑,2013,20(02):175-176+185.

[7]左策森.高速公路桥梁专业化养护工程施工技术探讨 [J].中国科技信息,2012,23(20):72. 